\title{
POTENSI PENGEMBANGAN TANAMAN ASLI SETEMPAT DALAM SISTEM AGROFORESTRI: STUDI KASUS DI DESA T'EBA KABUPATEN TIMOR TENGAH UTARA, NUSA TENGGARA TIMUR
}

\section{(The Potential of Native Plants Development in Agroforestry System: A Case Study of T'eba Village, Timor Tengah Utara Regency, Nusa Tenggara Timur)}

\author{
Hery Kurniawan ${ }^{1}$ \& Eko Pujiono ${ }^{2}$ \\ ${ }^{1}$ Balai Penelitian dan Pengembangan Teknologi Serat Tanaman Hutan Kuok \\ Jl. Raya Bangkinang Kuok Km. 9, Bangkinang, Riau 28294, Telp. 0762 - 7000121 \\ ${ }^{2}$ Balai Penelitian dan Pengembangan Lingkungan Hidup dan Kehutanan Kupang \\ Jl. Untung Surapati No. 7. PO. Box. 69, Kupang, NTT 85115, Telp. 0380 - 823357 \\ Email : herykurniawan2012@gmail.com
}

\begin{abstract}
Sandalwood (Santalum album Linn.), agarwood (Gyrinops versteegii (Gilg.) Domke) and papi wood (Exocarpus latifolia R.Br.) are native plants of Nusa Tenggara Timur (NTT) province with high economic value. T'eba village is one of the villages in Timor Tengah Utara (TTU) Regency which has a history of potential of sandalwood and papi wood. While, agarwood is an introduced species that shows quite good growth in the T'eba village. Unfortunately, the potential of these three native plant species development in T'eba Village had not yet been adequately expressed by research reports or other publication. Through structured-interview method and field observation, this research attemps to analyse the potential of theses native plants development in agroforestry system. Results indicated that the development of these three native plants in agroforestry system is high potential, especially viewed from the land suitability and social acceptability aspects, as well as the economic benefits to be gained. Such results could be useful for stakeholder to formulate plan or strategy in agroforestry development, especially in plant selection policy.
\end{abstract}

Keywords: Native plants of NTT, sandalwood, agarwood, papi wood, agroforestry system, social acceptability

\begin{abstract}
ABSTRAK
Cendana (Santalum album Linn.), gaharu (Gyrinops versteegii (Gilg.) Domke) dan kayu papi (Exocarpus latifolia R.Br.) merupakan tanaman asli Nusa Tenggara Timur (NTT) yang memiliki nilai ekonomi tinggi. Desa T'eba merupakan salah satu desa di Kabupaten Timor Tengah Utara (TTU) yang memiliki sejarah potensi jenis cendana dan kayu papi. Sementara jenis gaharu merupakan jenis introduksi yang menunjukkan pertumbuhan cukup bagus di Desa T'eba. Meski demikian, potensi pengembangan ketiga jenis ini di Desa T'eba belum banyak diungkap dalam bentuk laporan penelitian atau publikasi lainnya. Melalui metode wawancara terstruktur dan survei lapangan, penelitian ini mencoba menganalisis potensi pengembangan tanaman asli tersebut dalam sistem agroforestri. Hasil penelitian menunjukkan bahwa secara umum potensi pengembangan untuk ketiga jenis ini dengan pola agroforestri adalah tinggi, terutama dilihat dari aspek kesesuaian lahan dan tingkat penerimaan sosial masyarakat, serta manfaat ekonomi yang akan diperoleh. Hasil ini dapat dimanfaatkan oleh pihak terkait dalam merumuskan rencana atau strategi pengembangan sistem agroforestri, terutama dalam hal kebijakan pemilihan jenis tanaman.
\end{abstract}

Kata kunci: Tanaman asli NTT, cendana, gaharu, kayu papi, sistem agroforestri, tingkat penerimaan masyarakat 


\section{PENDAHULUAN}

Cendana (Santalum album Linn.), gaharu (Gyrinops versteegii (Gilg.) Domke) dan kayu papi (Exocarpus latifolia R.Br.) merupakan tanaman asli Nusa Tenggara Timur (NTT) yang sudah dikenal secara luas. Keberadaannya saat ini sudah mulai langka di lapangan disebabkan eksploitasi yang kurang terkontrol dan rendahnya keberhasilan penanamannya (Sumanto, Sutrisno \& Kurniawan, 2011). Sebelum tahun 2000, cendana masih merupakan komoditi andalan spesifik bagi Provinsi NTT maupun Indonesia. Cendana kini berada diambang kepunahan (Bano Et, 2001). Cendana di Indonesia pada saat ini termasuk kategori rentan (Vulnerable) berdasarkan kriteria IUCN (2015) dan hal ini telah terjadi sejak tahun 1998. Pada sisi yang lain, permasalahan ini semakin kompleks dengan adanya tekanan dari masyarakat dalam hal pemenuhan kebutuhan lahan untuk pangan.

Upaya peningkatan produktivitas hasil hutan kayu cendana, gaharu dan kayu papi terkendala oleh adanya tekanan masyarakat untuk kebutuhan lahan bercocok tanam. Selain itu, masyarakat belum sepenuhnya menguasai teknik budidaya cendana, gaharu dan kayu papi secara baik (Fatmawati, 2011). Sehingga perlu adanya terobosan teknologi yang mampu menjembatani antara kebutuhan pangan masyarakat dan upaya pelestarian dan pengembangan cendana di masyarakat. Sebagai contoh, di Desa Asumanu, Kecamatan Raihat, Kabupaten Belu, NTT, meskipun potensi untuk mengembangkan cendana sangat besar, namun berdasarkan hasil pengamatan kelestarian fungsi produksi, fungsi ekologi, dan fungsi sosial menunjukan pengelolaannya belum lestari
(Widiyanti, Purnaweni, \& Soeprobowati, 2013).

Hasil hutan bukan kayu (cendana) merupakan hasil jangka panjang, oleh karena itu diperlukan adanya tambahan teknologi yang sesuai dengan kebutuhan petani di lapangan. McWilliam (2005) berpendapat bahwa cendana memiliki potensi untuk dikembangkan sebagai pertanaman karena periode waktu yang dibutuhkan untuk mendapatkan kayu teras matang kurang lebih 15-20 tahun. Namun demikian, tidak diharapkan bahwa tanaman dikembangkan dengan pola monokultur cendana disebabkan karakteristik parasit cendana menuntut cendana bergantung pada tanaman inang sepanjang hidupnya, sehingga pola tanam campuran cendana dengan jenis tanaman inang dibutuhkan.

Agroforestri sebagai salah satu bentuk penggunaan lahan, diyakini mampu memberikan sumbangan terhadap upaya mengatasi masalah kerusakan lingkungan dan sekaligus sebagai salah satu pendekatan dalam pengentasan kemiskinan di pedesaan (Rajati, Kusmana, Darusman, \& Saefuddin, 2006). Kegiatan domestikasi pohon untuk dikembangkan pada sistem agroforestri saat ini telah masuk dekade ketiga. Pada dekade ini, kegiatan diarahkan pada pengembangan serta perluasan ilmu pengetahuan dan teknologi (Iptek) sebagai dasar domestikasi pohon-pohon agroforestri dan penelitian terapan untuk mendukung pengembangan program dalam rangka meningkatkan perekonomian/ mata pencaharian petani kecil/miskin (Leakey et al., 2012). Pola penanaman agroforestri diharapkan secara simultan menjadi solusi terhadap kebutuhan petani, tujuan pelestarian dan usaha pengembangan cendana di lahan masyarakat. 
Input pola pertanian berupa tanaman pertanian non kehutanan diharapkan mampu menjawab kebutuhan petani dalam jangka pendek. Kebutuhan jangka menengah dapat dipenuhi dengan jenisjenis MPTS (Multi Purpose Trees System), juga alternatif lainnya seperti gaharu. Gaharu akan memberikan hasil dalam jangka menengah dengan memanennya dalam 10-15 tahun. Hal ini disebabkan karena nilai ekonominya dan peluang pasar yang menjanjikan. Sedangkan kayu papi, merupakan kayu aromatik yang dapat digunakan sebagai substitusi cendana. Kayu Papi memiliki peluang pasar yang cukup besar, mengingat semakin menurunnya suplai kayu cendana di pasaran.

Penanaman kayu papi dengan pola agroforestri diharapkan selain dapat memenuhi kebutuhan jangka pendek dan jangka panjang bagi petani, juga akan meningkatkan suplai kayu papi di pasaran, dan pada akhirnya mampu mengurangi laju penurunan populasi cendana.

Pengembangan ketiga jenis ini dengan teknik agroforestri, tentunya memerlukan studi terhadap kesiapan dan minat masyarakat tersebut. Jenis yang sesuai, masyarakat yang siap (paham dan trampil), serta tersedianya materi dan iptek yang mendukung pengembangan ketiga jenis tersebut merupakan faktor utama yang sangat berpengaruh terhadap tingkat keberhasilan pengembangan ketiga jenis tersebut. Tulisan ini merupakan salah satu studi kasus yang memberikan gambaran tentang potensi pengembangan ketiga jenis tersebut serta kesiapan masyarakat dalam menerimanya, dalam rangka memberikan dukungan dari aspek iptek berdasarkan penelitian survey.

\section{METODE PENELITIAN}

\section{A. Lokasi dan Waktu Penelitian}

Penelitian dilakukan di Desa T'eba, Kecamatan Biboki Tanpah, Kabupaten TTU, Provinsi NTT. Penelitian dilakukan pada bulan Juni Tahun 2015.

\section{B. Metode Penelitian}

Penelitian ini dilakukan menggunakan metode survei sosial secara langsung dengan melakukan wawancara yang terstruktur dan melalui kuesioner. Penentuan responden dilakukan secara purposive, terhadap masyarakat petani Desa Teba, dan terhadap tokoh-tokoh kunci yang ada. Jumlah responden untuk masyarakat petani adalah 38 responden yang terdiri dari 3 Wanita dan 35 Laki-laki. Sementara untuk tokoh kunci diperoleh sampel sebanyak 7 (tujuh) orang yang terdiri dari Kepala Desa, 2 (dua) orang mantan Kepala Desa, dan seorang Sekretaris Desa, serta 3 (tiga) orang Ketua Kelompok Tani.

Dipilihnya Desa T'eba sebagai lokasi penelitian adalah berdasarkan survei lokasi calon plot agroforestri yang akan dibangun. Pemilihan calon lokasi plot uji coba agroforestri berdasarkan beberapa kriteria, yakni : 1. Jarak lokasi calon plot ke sumber air, 2. Aksesibilitas sampai di lokasi calon plot, 3. Bentuk lahan calon plot (rata, bergelombang, miring), 4. Kepadatan naungan (berat, sedang, ringan), 5. Ketersediaan tenaga kerja (jarak ke perkampungan dan minat), 6. Resiko gangguan dari ternak dan api, 7. Status kepemilikan lahan (pribadi/komunal). Selain itu, di Desa T'eba ini, juga terdapat tegakan kayu papi yang tumbuh secara alami. Sedangkan untuk jenis cendana dan gaharu diketahui dapat tumbuh baik di desa ini. 


\section{HASIL DAN PEMBAHASAN}

\section{A. Gambaran Umum Lokasi Penelitian}

\section{Kondisi Umum}

Secara administratif Desa T'eba terletak di Kecamatan Biboki Tanpah, Kabupaten TTU, Provinsi Nusa Tenggara Timur. Desa T'eba dibatasi oleh Desa Takberi di sebelah utara, Desa Triumanu di sebelah selatan, Desa Teba Timur di sebelah timur dan Desa Oenbit di sebelah barat (Gambar 1). Desa T'eba terletak pada ketinggian sekitar 1.500 meter dari permukaan laut. Terkait kondisi iklim, suhu rata-rata harian di desa ini tercatat sekitar $24^{\circ} \mathrm{C}$ dan memiliki jumlah bulan basah (bulan hujan) maksimal 6 bulan. Berdasarkan hasil penelitian Sumardi dan kawan-kawan (2016), Kecamatan Biboki Tanpah (termasuk desa T'eba) masuk dalam kelas kesesuaian 3 dan 4 . Kelas sesuai 3 dan 4 umumnya memiliki jenis tanah Kambisol Ustik dan Grumusol. Beberapa karakteristiknya adalah ketersediaan oksigen baik, kadar lengas antara 1,06-1,46 gr/ $/ \mathrm{cm}^{3}$. Kandungan pasir rata-rata $74,33 \%$ dan $70,33 \%$, kandungan debu rata-rata adalah $13,5 \%$ dan $21 \%$, serta kandungan litanya adalah $12,17 \%$ dan $8,67 \%$. Kedalaman solum rata-rata adalah $<40 \mathrm{~cm}$, kandungan $\mathrm{N}$ ratarata $0,27 \%$ dan $0,33 \%$, kandungan $\mathrm{P} 2 \mathrm{O} 5$ ratarata $68,36 \mathrm{ppm}$ dan $63,6 \mathrm{ppm}$. Sedangkan kandungan $\mathrm{K} 2 \mathrm{O}$ adalah 0,75 dan 0,65 me/100.

Berdasarkan Profil Desa tahun 2014, desa ini memiliki lahan luas sekitar 1.178 hektar yang dipergunakan untuk pertanian, perkebunan, pemukiman, hutan dan untuk prasarana umum lainnya (Tabel 1).

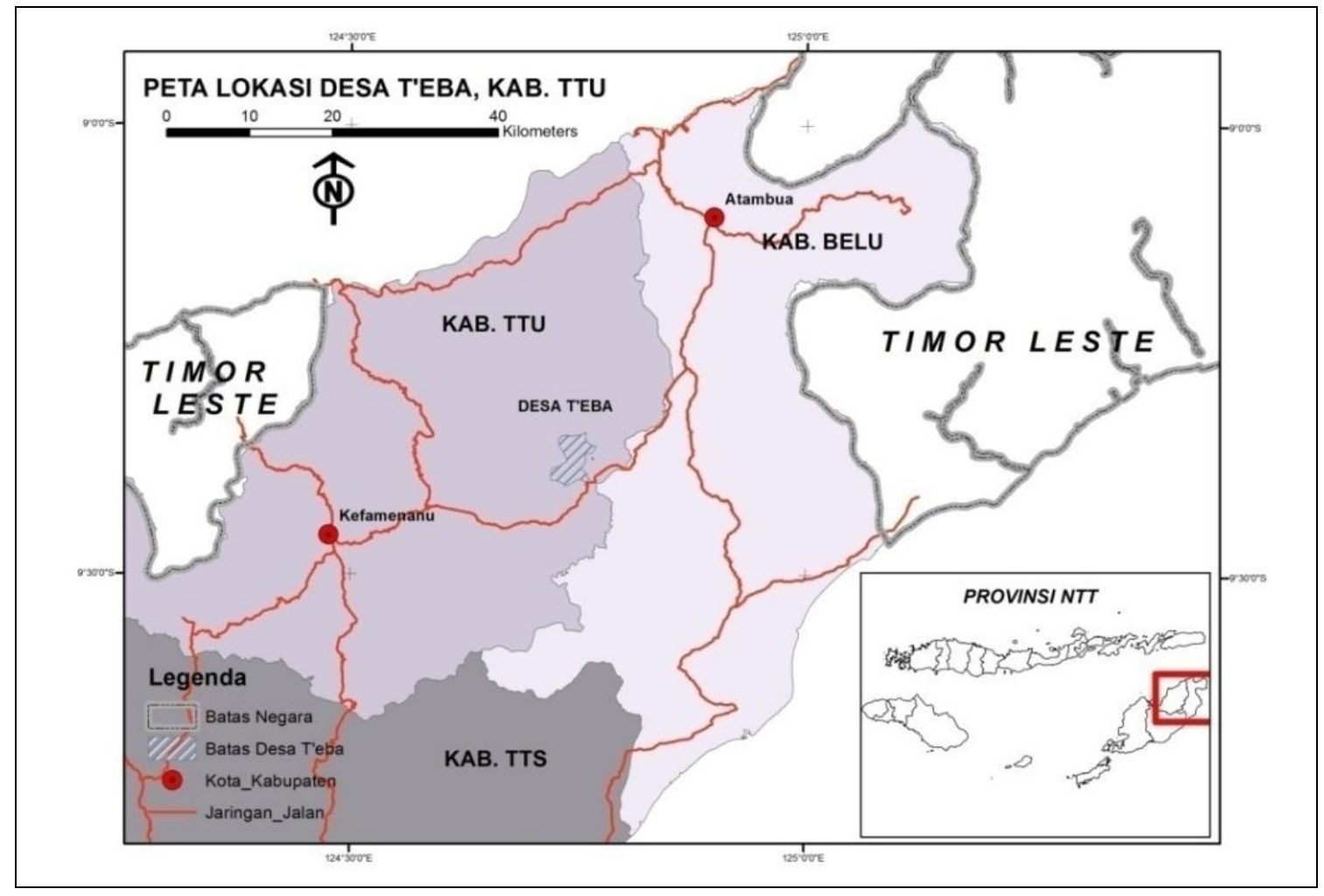

Gambar 1. Peta lokasi Desa T'eba

Figure 1. Map of T'eba village location 
Tabel 1. Penggunaan lahan di Desa T'eba

Table 1. Land use in T'eba Village

\begin{tabular}{lr}
\hline Jenis Prenggunaan Lahan (Type of land use) & Luas (large $)$ (ha) \\
\hline Sawah tadah hujan & 40 \\
Lahan kering - tegal/ladang & 150 \\
Lahan kering - pemukiman & 10 \\
Lahan kering - pekarangan & 568 \\
Perkebunan - kebun rakyat & 200 \\
Fasilitas umum - tanah kas desa & 0,9 \\
Fasilitas umum - lap olahraga & 1 \\
Fasilitas umum - kantor desa & 1,5 \\
Fasilitas umum - makam & 4 \\
Fasilitas umum - jalan & 3 \\
Hutan - Hutan Produksi Terbatas & 200 \\
\hline Total (Total) & $\mathbf{1 . 1 7 8 , 4}$ \\
\hline
\end{tabular}

Sumber: Profil Desa T'eba tahun 2014

Source : Profile of T'eba Village 2014

\section{Potensi Sumber Daya Alam}

Potensi sumber daya alam di Desa T'eba didominasi oleh sektor pertanian. Komoditas utama sektor pertanian tanaman pangan adalah padi ladang. Komoditas tanaman pangan yang lain adalah sayuran jenis tomat dan terung, kacang turis dan talas. Selain itu, terdapat juga komoditas buah-buahan seperti, mangga, pepaya, pisang dan nangka yang dapat ditemukan di ladang, kebun maupun pekarangan rumah. Berdasarkan luasannya, komoditas padi ladang memiliki luasan terbesar, diikuti oleh mangga, pisang, pepaya dan nangka. Sedangkan untuk produktivitas tanaman tertinggi adalah padi ladang yakni sekitar 1,5 ton per hektar dan kedua adalah kemiri (100 kw/ha) (Tabel 2).

Selain tanaman pertanian, di Desa T'eba juga terdapat tanaman-tanaman perkebunan, meskipun luas penanamannya tidak terlalu besar. Komoditas perkebunan tersebut berupa jambu mente, kemiri dan kelapa. Sebagaimana diketahui bahwa kondisi iklim semi arid NTT berpengaruh pada sebagian besar petani $(81 \%)$ yang menggantungkan hidupnya pada sektor pertanian lahan kering (Njurumana, Hidayatullah \& Butarbutar, 2008). Untuk penggunaan lahan berupa hutan, komoditas yang ada yaitu: hasil hutan kayu (jati dan mahoni) serta hasil hutan bukan kayu (bambu dan madu hutan). Gambaran mengenai komoditas potensial, luasan dan produktivitasnya disajikan pada Tabel 2 .

Masyarakat mempergunakan hasil tanamannya untuk memenuhi kebutuhannya sendiri dan sebagian juga dijual. Mekanisme pemasaran yang ada di Desa T'eba, baik untuk tanaman pangan, buah, perkebunan maupun hasil hutan, sebagian besar melalui jasa pengepul/tengkulak (Anonim, 2014). Selain bertani, masyarakat/petani juga memelihara hewan sebagai ternak. Jenis populasi ternak (hewan besar) yang dominan adalah sapi, kuda, babi, kambing, anjing dan kucing, sementara ternak unggasnya berupa ayam dan bebek.

Sumberdaya air merupakan kebutuhan utama dalam mendukung aktivitas sektor pertanian dan peternakan serta untuk kehidupan masyarakat sehari-hari. Di Desa T'eba, potensi sumberdaya air terdiri dari dua mata air, empat sumur gali, satu pipa, dua embung dan fasilitas perpipaan hasil swadaya masyarakat. Semua dalam kondisi baik dan dimanfaatkan oleh total 300 Kepala Keluarga (KK). 
Tabel 2. Komoditas potensial di Desa T'eba, luasan dan produktivitasnya

Table 2. Potential Commodities in T'eba Village, its area and productivity

\begin{tabular}{lrr}
\hline Komoditas (Commodity) & Luas (Large) (ha) & Produktivitas (Productivity) \\
\hline Tan. Pertanian - padi ladang & 40 & 1,5 ton/ha \\
Tan. Pertanian - tomat & & 0,01 ton/ha \\
Tan. Pertanian - terong & & 0,01 ton/ha \\
Tan. Pertanian - kacang turis & & 0,1 ton/ha \\
Tan. Pertanian - talas & 4 & 0,1 ton/ha \\
Tan. Buah-buahan - mangga & 1,6 & - \\
Tan. Buah-buahan - pepaya & 2,7 & - \\
Tan. Buah-buahan - pisang & 0,5 & - \\
Tan. Buah-buahan - nangka & 0,5 & - \\
Tan. Perkebunan - kelapa & 4,6 & $24 \mathrm{kw} / \mathrm{ha}$ \\
Tan. Perkebunan - jambu mente & 1,5 & $6,66 \mathrm{kw} / \mathrm{ha}$ \\
Tan. Perkebunan - kemiri & & $100 \mathrm{kw} / \mathrm{ha}$ \\
Hasil hutan kayu - jati & & $6 \mathrm{~m}^{3} / \mathrm{ha}$ \\
Hasil hutan kayu - mahoni & & $3,5 \mathrm{~m} \mathrm{~m}^{3} / \mathrm{ha}$ \\
Hasil hutan bukan kayu - bambu & & $5 \mathrm{~m}^{3} / \mathrm{ha}$ \\
Hasil hutan bukan kayu - madu & & $30 \mathrm{liter} / \mathrm{th}$ \\
\hline
\end{tabular}

Sumber : Profil Desa T'eba tahun 2014

Source : Profile of T'eba Village 2014

3. Potensi Sumber Daya Manusia dan Kesejahteraan Masyarakat

\section{a. Kependudukan}

Data kependudukan tahun 2014 menyebutkan bahwa jumlah penduduk Desa T'eba adalah sekitar 1.188 orang, dengan rincian 542 orang laki-laki dan 646 orang perempuan. Jumlah kepala keluarga sebanyak
$301 \mathrm{KK}$, dengan rata jumlah anggota per KK sebanyak 4 orang. Kepadatan penduduk sebesar 0,84 atau sekitar $1 \mathrm{jiwa} / \mathrm{km}^{2}$. Struktur kependudukan menunjukkan fenomena piramida, dimana penduduk usia muda lebih dominan daripada yang usia tua. Grafik komposisi penduduk Desa T'eba dapat dilihat pada Gambar 2.

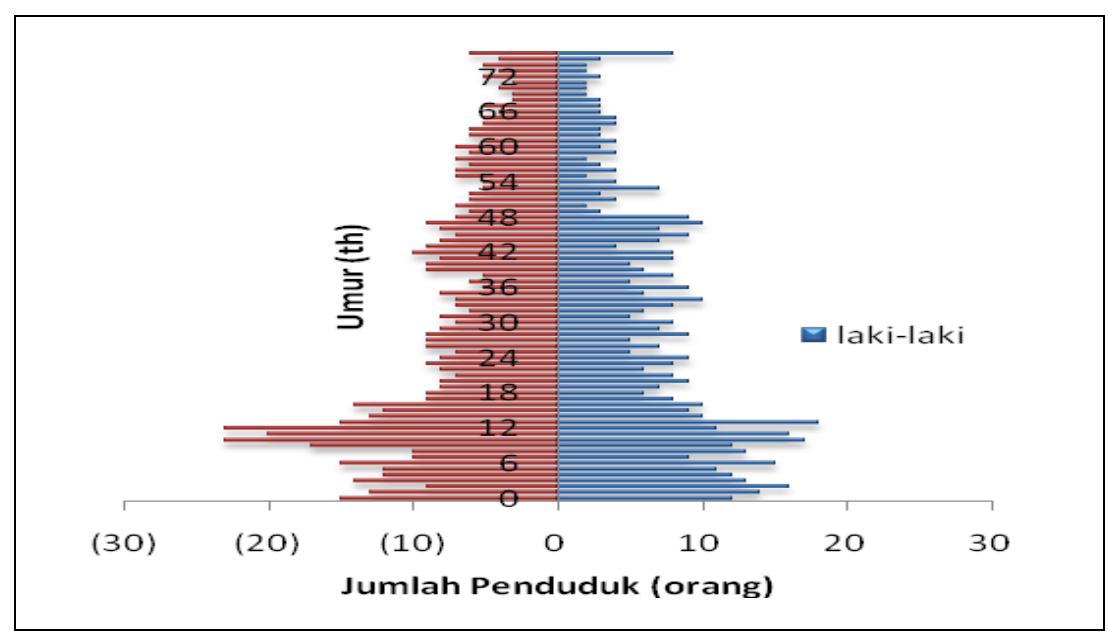

Gambar 2. Komposisi penduduk berdasarkan usia Figure 2. Population composition based on age 


\section{b. Pendidikan}

Berdasarkan tingkat pendidikan, sebagian besar penduduk Desa T'eba menyelesaikan pendidikan pada tingkat sekolah dasar (sekitar 37\%), diikuti oleh penduduk yang tamat SLTP (17\%) dan tamat SLTA (9\%) (Pemerintah Desa T'eba, 2014). Distribusi jumlah penduduk berdasarkan tingkat pendidikan selengkapnya disajikan pada Gambar 3.

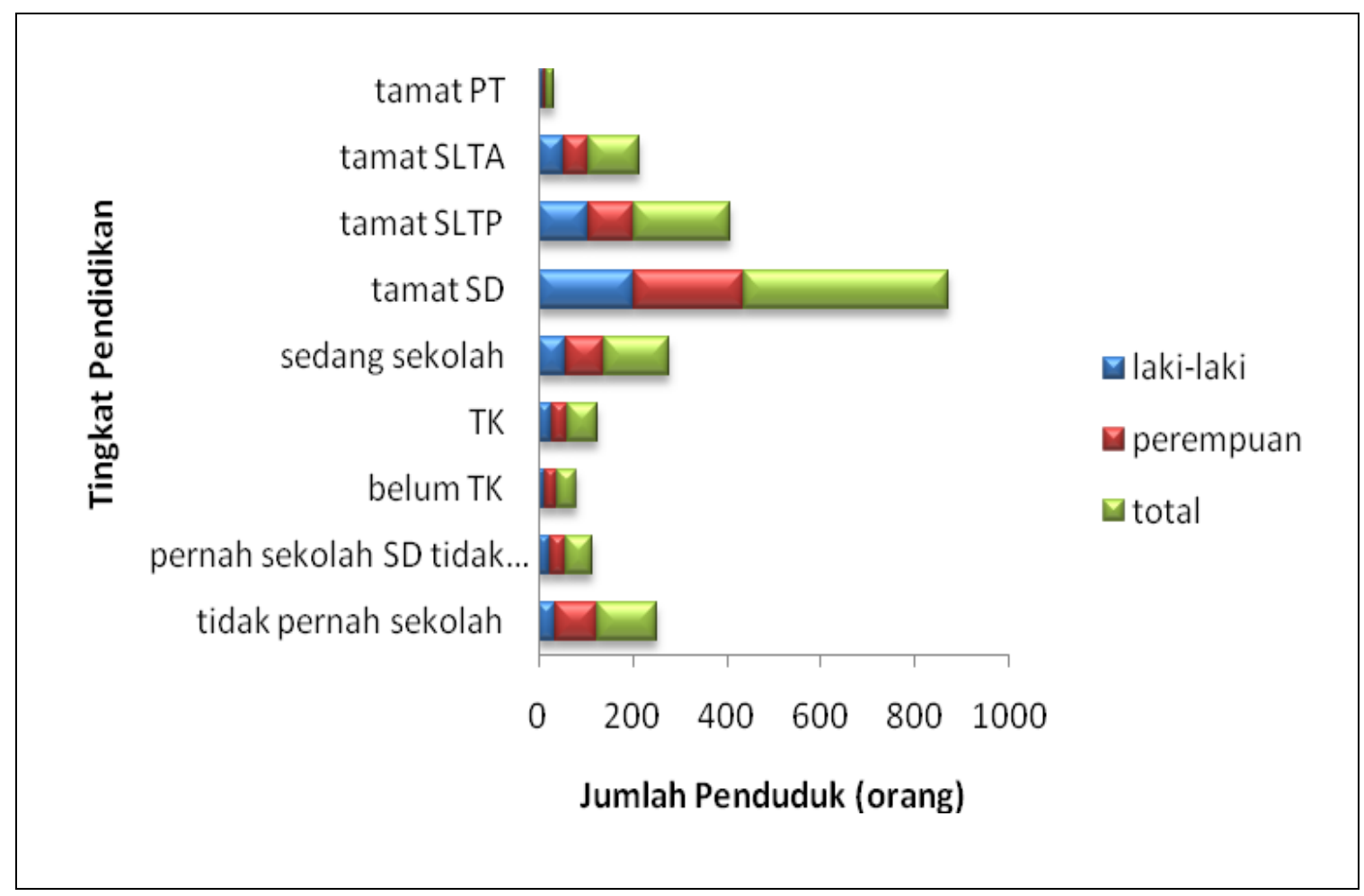

\section{Gambar 3. Jumlah penduduk berdasar tingkat pendidikan Figure 3. Population based on educational level}

\section{c. Mata pencaharian}

Pemerintah Desa T'eba tahun 2014 melaporkan bahwa sebagian besar penduduk bermata pencaharian sebagai petani, hanya beberapa orang saja yang bekerja sebagai karyawan swasta, pedagang dan Pegawai Negeri Sipil. Dari 301 Kepala Keluarga (KK) yang ada, $256 \mathrm{KK}$ diantaranya (atau sekitar $85 \%$ ) bermatapencaharian sebagai petani.

\section{Ketenagakerjaan}

Data Pemerintah Desa T'eba tahun 2014 melaporkan bahwa jumlah Penduduk yang masuk usia kerja produktif sebanyak 544 orang, dengan rincian 253 orang laki- laki dan 291 orang perempuan. Dengan kata lain proporsi tenaga kerja yang dikategorikan sebagai usia produktif di Desa T'eba sekitar 46\% dari jumlah total jumlah penduduk.

\section{Tingkat kesejahteraan}

Berdasarkan tingkat kesejahteraan keluarga, sebagian besar keluarga yang ada Desa T'eba termasuk dalam kategori sejahtera 1 dan 2. Jumlah KK sangat miskin dan miskin sekitar $30 \%$ dari total jumlah KK. Distribusi jumlah KK berdasarkan tingkat kesejahteraannya disajikan pada Tabel 3. 


\section{Tabel 3. Kesejahteraan keluarga}

Table 3. Family welfare

\begin{tabular}{lc}
\hline \multicolumn{1}{c}{ Kategori tingkat sejahtera (Prosperity category) } & Jumlah (Quantity) (KK) \\
\hline Keluarga prasejahtera (sangat miskin) & 22 \\
Sejahtera 1 (miskin) & 84 \\
Sejahtera 2 & 92 \\
Sejahtera 3 & 103 \\
Sejahtera 3 - plus & - \\
\hline Total (Total) & $\mathbf{3 0 1}$ \\
\hline
\end{tabular}

Sumber : Profil Desa T'eba tahun 2014

Source : Profile of T'eba Village

\section{B. Aspek Pengelolaan Lahan dan Ekonomi 1. Pengelolaan Lahan}

Masyarakat di desa T'eba membagi penggunaan lahan menjadi sawah tadah hujan, ladang/kebun dan pekarangan. Sawah tadah hujan pada umumnya ditanami padi, terletak dekat dengan pemukiman (dengan radius terjauh sekitar $1 \mathrm{~km}$ ) dan dilakukan pada lahan yang relatif datar sampai landai. Ladang/ kebun biasanya di tanami jagung, kacang-kacangan, umbi-umbian dan tanaman kayu/tanaman kehutanan. Ladang/kebun pada umumnya terletak agak jauh dari pemukiman $(>1 \mathrm{~km})$ dan memiliki tingkat kemiringan lahan landai sampai curam. Penggunaan lahan yang lainnya adalah pekarangan, yaitu pemanfaatan lahan di sekitar rumah tempat tinggal.

Kegiatan pertanian sudah dilakukan oleh masyarakat T'eba sejak lama, sejak zaman penduduk pertama dulu menetap di Desa Teba. Hasil rekapitulasi kuisioner menunjukkan bahwa sekitar 34\% ladang/kebun yang dibuat, pada awalnya adalah semak belukar. Sedangkan $20 \%$ responden menyatakan bahwa lahan yang dibuat ladang/kebun sebelumnya adalah lahan yang memang kosong, sementara sisa responden yang lain memilih tidak menjawab. Informasi ini menunjukkan bahwa kondisi kebun masyarakat Desa T'eba merupakan pertanian lahan kering. Kondisi lahan di Pulau
Timor termasuk daerah yang dekat dengan perbatasan NKRI-Timor Leste, memang didominasi oleh lahan kering (Priyanto \& Diwyanto, 2014).

Terkait dengan sistem agroforestri yang berkembang, hasil observasi lapangan menemukan bahwa memang sudah ada beberapa petani yang menanam tanaman pangan dan tanaman kayu secara bersamaan. Beberapa pola yang bisa diidentifikasi adalah pola pohon batas (trees along border) dan pola campur (mixed). Hasil rekapitulasi responden menunjukkan bahwa sekitar $40 \%$ responden menanam tanaman kayu dan tanaman pangan secara bersamaan dengan pola campur (jarak tanam tidak beraturan), hanya sebagian kecil yang menanam dengan pola trees along border. Kebanyakan petani $( \pm 60 \%)$ menanam tanaman pangan terpisah dengan tanaman kayu (lahannya terpisah), dengan pertimbangan agar tajuk tanaman kayu tidak menghambat pertumbuhan tanaman pangan. Hal ini sesuai dengan pernyataan Yanti (2012), bahwa tanaman pangan masih mendominasi lahan wanatani. Meskipun sebagian besar sudah sesuai dengan kelas kesesuaian lahannya, namun kondisi ini dapat berakibat pada semakin terkurasnya unsur hara mikro lahan wanatani semi arid. Permasalahan ini sebagaimana dikemukakan oleh Banjarnahor (2016), 
berdasarkan hasil penelitiannya di Tanzania terkait produksi pangan di daerah minim air dan kesuburan tanah, dilaporkan bahwa persoalan yang juga krusial untuk diatasi adalah kendala umum bersama yang dihadapi petani yaitu rendahnya produksi tanaman sehingga terjadi persaingan penggunaan biomassa tanaman untuk kebutuhan manusia, ternak, dan tanah. Faktor pembatas aktual dalam produksi tanaman lokal perlu diinvestigasi lebih lanjut. Dalam konteks ini maka konsep agroforestri dapat berperan sebagai solusi untuk mengatasi permasalahan lahan.

Jenis tanaman pangan yang dominan adalah padi dan jagung, sedangkan tanaman kayu yang dominan adalah jati dan mahoni. Secara lengkap rekapitulasi jenis tanaman yang ada di desa T'eba berdasarkan pendapat responden disajikan pada Tabel 4. Dalam hal diversifikasi pertanian, NTT mengalami pola yang menurun namun tetap berada di atas indeks nasional. Menurut Saparita (2005), hal ini mengindikasikan bahwa pada wilayah tersebut pertanian sedang berjalan ke arah spesialisasi. Di sisi lain, pertumbuhan tanaman cendana dan kayu papi yang cukup lambat juga menjadi alasan kuat untuk dapat ditanam bersama tanaman semusim. Hasil penelitian (Kurniawan, 2012) menunjukkan bahwa tingkat persaingan tajuk cendana pada Kabupaten TTU, termasuk Desa T'eba secara umum masih rendah. Hal ini berarti masih tersedia cukup ruang untuk budidaya tanaman pertanian semusim.

Tabel 4. Jenis Tanaman yang dikembangkan di Desa T'eba

Table 4. Plants species developed in T'eba village

\begin{tabular}{lc}
\hline $\begin{array}{c}\text { Jenis tanaman } \\
\text { (Plant type })\end{array}$ & $\begin{array}{c}\text { Prosentase jawaban responden } \\
\text { (Percentage of respondents' answers) }\end{array}$ \\
\hline Tanaman Pangan: & $93 \%$ \\
Jagung & $78 \%$ \\
Padi & $48 \%$ \\
Ubi & $15 \%$ \\
Kacang & \\
Tanaman Kayu: & $93 \%$ \\
Jati & $78 \%$ \\
Mahoni & $4 \%$ \\
Gmelina & \\
Tanaman lainnya (buah, MPTS): & $67 \%$ \\
Mangga & $52 \%$ \\
Mente & $19 \%$ \\
Pisang & $15 \%$ \\
Pepaya & $15 \%$ \\
Kemiri & $7 \%$ \\
Asam & $7 \%$ \\
Kelapa & \\
\hline
\end{tabular}

Keterangan : 27 dari 35 responden menjawab pertanyaan tentang jenis tanaman $(\mathrm{n}=27)$

Remarks: 27 of 35 respondents answered questions about plant types

Sumber: Pengolahan data primer, 2015

Source: Primary data processing, 2015 
Diversifikasi usaha tani sudah lama dipraktekkan petani lahan kering di NTT. Beberapa jenis tanaman dikombinasikan oleh petani secara arif dalam diversifikasi usaha tani. Jumlah tanaman jagung yang banyak disebabkan adanya Program Jagungisasi yang merupakan salah satu program unggulan Pemda NTT. Selain mengusahakan berbagai tanaman pangan seperti padi, jagung dan ubi-ubian untuk memenuhi kebutuhan pangan, petani dapat mengusahakan kacang-kacangan yang dapat memberikan manfaat bagi petani baik dalam hal penyediaan pangan sumber protein juga yang penting adalah dapat meningkatkan pendapatan petani karena kacang-kacangan memiliki harga jual yang tinggi dibanding jenis pangan lainnya (Leki, 2010).

Kepala rumah tangga merupakan pelaksana utama dalam aktivitas bertani. Namun begitu, anggota keluarga lain juga turut dilibatkan dalam aktivitas pertanian. Hasil rekapitulasi responden terkait pembagian kerja dalam aktivitas bertani menunjukkan bahwa sekitar $88 \%$ istri, $64 \%$ anak dan $24 \%$ lansia (>60 tahun) turut membantu kepala rumah tangga dalam aktivitas pertanian. Kondisi ini seperti yang dijelaskan oleh Zypchyn (2012) bahwa wanita memainkan peran penting dalam usaha tani pangan organik dan keberlanjutannya. Usaha tani pangan termasuk kebun yang relatif jauh lokasinya dari pekarangan, meski dipandang sebagai salah satu bagian sistem pertanian lahan kering masyarakat NTT, dan mesti dipandang sebagai extended home garden bagi masyarakat NTT (Ngongo dan Marawali, 2016).

Apabila melihat data luasan lahan kering baik pada tegal/ladang, pemukiman, pekarangan dan kebun, jumlah total luasnya adalah 928 hektar. Berdasarkan informasi yang dikumpulkan diperoleh keterangan bahwa ada sekitar 40\% masyarakat yang menanam tanamannya secara campuran. Bila mengacu pada data ini maka ada sekitar 371 hektar lahan pertanian lahan kering yang dapat dimanfaatkan untuk penanaman jenis cendana, kayu papi dan gaharu dengan pola agroforestri. Tentunya potensi lainnya pada pola tanaman tunggal juga sangat mungkin untuk dikembangkan. Penanaman dengan pola agroforestri sangat memungkinkan sebagaimana yang dinyatakan oleh (Hendrisman et al., 2001) pembudidayaan kayu cendana dapat dilakukan pada batas-batas lahan usaha pertanian, batas padang penggembalaan dan pematang kebun yang dapat berfungsi ganda yaitu sebagai penguat teras dan tanda batas kepemilikan lahan. Pembudidayaan dapat juga melalui reboisasi lahan agroforestri dengan pola Hutan Tanaman Industri yang berwawasan kemasyarakatan.

\section{Ekonomi masyarakat}

Bahasan aspek ekonomi difokuskan kepada tingkat konsumsi (biaya), pendapatan dan analisis usaha tani aktivitas pertanian. Estimasi seberapa besar pengeluaran petani dalam satu tahun difokuskan pada pengeluaran untuk konsumsi dan pengeluaran untuk kegiatan sosial. Hasil rekapitulasi responden menunjukkan bahwa besarnya pengeluaran petani adalah sekitar 8,3 juta rupiah per tahun atau sekitar 700 ribu rupiah per bulan. Selengkapnya mengenai pengeluaran petani disajikan pada Tabel 5.

Kegiatan pertanian merupakan sumber utama penghasilan masyarakat. Sebagian besar masyarakat dikategorikan sebagai petani subsisten, dimana petani membudidayakan tanaman pangan secukupnya untuk memenuhi kebutuhan sendiri. Pertanian subsisten secara umum menggunakan masukan sarana produksi (input) rendah yang berasal dari bahan yang tersedia di lokasi usahatani, yaitu benih dari hasil panen musim tanam sebelumnya, pupuk kandang dosis rendah, dan pengelolaan tanaman secara tradisional (Sutoro, 2015). 
Tabel 5. Pengeluaran petani

Table 5. Farmers expenditure

\begin{tabular}{|c|c|c|}
\hline $\begin{array}{l}\text { Pengeluaran/konsumsi (Expenditures/ } \\
\text { consumption) }\end{array}$ & $\begin{array}{c}\text { Konsumsi/tahun } \\
\text { (consumption/year) }\end{array}$ & $\begin{array}{c}\text { Nilai }(\text { Price }) \\
\text { (Rp/ tahun) }\end{array}$ \\
\hline \multicolumn{3}{|l|}{ Komsumsi: } \\
\hline Beras & $300 \mathrm{~kg}$ & 2.550 .000 \\
\hline Minyak Tanah & 30 liter & 150.000 \\
\hline Minyak Goreng & 50 liter & 600.000 \\
\hline Kayu Bakar & 190 ikat & 950.000 \\
\hline Listrik & - & 360.000 \\
\hline Anak Sekolah & 1 anak & 1.200 .000 \\
\hline Bensin/ transport & 360 liter & 360.000 \\
\hline \multicolumn{3}{|l|}{ Sosial: } \\
\hline Acara Adat & 3-4 kali & 1.000 .000 \\
\hline Acara Agama & $10-12$ kali & 200.000 \\
\hline Acara Keluarga & 3-4 kali & 1.000 .000 \\
\hline \multicolumn{2}{|l|}{ TOTAL (Total) } & 8.370 .000 \\
\hline
\end{tabular}

Keterangan (remarks): asumsi harga beras (assumption of rice price): Rp. 8.500,-/kg; harga minyak tanah kerosene price : Rp. 5.000,-/liter; harga minyak goreng (cooking oil price): Rp. 12.000,-/botol; harga kayu Bakar (firewood price): Rp. 5.000,-/ikat (sumber harga (price source): Kec. Biboki Tan Pah, 2014)

Sumber : Pengolahan data primer, 2015

Source : Primary data processing, 2015

Meskipun menurut Lassa (2009), kontribusi food crops terhadap Pendapatan Domestik Regional Bruto (PDRB) NTT turun drastis dari lebih dari $53.7 \%$ di akhir tahun 1960an hingga ke level 21\% ditahun 2006, namun sebagian besar penduduk NTT masih menggantungkan hidupnya pada sektor pertanian (Leki, 2010). Terlepas dari tipe petani subsisten tersebut, dalam kajian ini hasil produksi pertanian atau hasil lainnya akan dikuantitatifkan untuk dapat mengetahui seberapa besar sebenarnya pendapatan yang diperoleh petani. Hasil rekapitulasi responden menyebutkan bahwa besarnya pendapatan petani sekitar 8,6 juta rupiah per tahun atau sekitar 716 ribu rupiah per bulan seperti dijelaskan Tabel 6 .

\section{Tabel 6. Pendapatan petani}

Table 6. Farmers income

\begin{tabular}{lcr}
\hline Sumber Pendapatan (Revenue sources) & Produksi/tahun (Production/year) & Rp/tahun (Rp/year) \\
\hline Hasil Pertanian/ Perkebunan: & & \\
Jagung & $325 \mathrm{~kg}$ & 1.300 .000 \\
Padi & $400 \mathrm{~kg}$ & 3.000 .000 \\
Mente & $80 \mathrm{~kg}$ & 800.000 \\
Hasil Ternak: & $1 \mathrm{ekor}$ & \\
Sapi & $1 \mathrm{ekor}$ & 2.000 .000 \\
Babi & & 1.500 .000 \\
Total (Total) & & 8.600 .000 \\
\hline
\end{tabular}

Keterangan (remarks): asumsi harga jagung (assumption of corn price): Rp. 4.000,-/kg; harga padi (rice price): Rp. 7.500,-/liter; harga mente (cashew nut price) : Rp. 10.000,-/kg

Sumber : Pengolahan data primer, 2015 (Source : Primary data processing, 2015) 
Hasil perhitungan menunjukkan bahwa pengeluaran dan pendapatan petani hampir sama. Ini sejalan dengan fakta yang menyebutkan bahwa tipe petani di Desa T'eba adalah petani subsisten, dimana hasil pertanian hanya cukup untuk pemenuhan kebutuhan sendiri. Hal ini menunjukkan adanya kondisi sebagaimana yang disebutkan oleh Leki (2010) bahwa dari segi ketersediaan sesungguhnya masyarakat NTT pada umumnya mampu berswasembada pangan, namun kondisi ini perlu diwaspadai karena pangan yang dihasilkan sebagian akan dijual untuk memenuhi kebutuhan hidup lainnya. Sebagaimana dijelaskan oleh Maguantara
(2005), bahwa umumnya petani sudah mengalami ketergantungan terhadap teknologi pertanian, yang mana semua kebutuhannya, kecuali tenaganya sendiri, diadakan oleh pihak lain dan harus mengeluarkan uang untuk mendapatkannya.

Selain perbandingan antara besarnya pengeluaran dan pendapatan rumah tangga petani seperti diuraikan sebelumnya, dilakukan juga analisis usaha tani untuk mengetahui sampai sejauh mana biaya yang dikeluarkan dalam bidang pertanian dibandingkan dengan pendapatan dari aktivitas pertanian. Hasil rekapitulasi analisis usaha tani disajikan pada Tabel 7.

Tabel 7. Analisis usaha tani untuk lahan sekitar 0,25 ha

Table 7. Analysis of farming for 0.25 hectar land

\begin{tabular}{|c|c|c|}
\hline $\begin{array}{l}\text { Komponen Biaya/ Pendapatan } \\
\text { (Cost / Revenue Component) }\end{array}$ & $\begin{array}{c}\text { Jumlah } \\
\text { (amount) }\end{array}$ & $\begin{array}{c}\text { Keterangan } \\
\text { (Remarks) }\end{array}$ \\
\hline \multicolumn{3}{|l|}{ Biaya: } \\
\hline - Persiapan Lahan & & Agus-Okt \\
\hline Bahan (cangkul, sabit, fungisida) & 250.000 & \\
\hline Ongkos Kerja & 300.000 & \\
\hline - Penamaman & & Des-Jan \\
\hline Bibit (padi, jagung, kacang) & 300.000 & \\
\hline Bibit tan kayu (jati/ mahoni) & - & Cabutan alam \\
\hline Ongkos Kerja & 200.000 & \\
\hline - Pemeliharaan & & Feb-Apr \\
\hline Pemeliharaan \& pemupukan & 150.000 & \\
\hline Ongkos Kerja & 100.000 & \\
\hline - Pemanenan & & Mei-Jun \\
\hline Bahan (karung) & 50.000 & \\
\hline Ongkos Kerja & 250.000 & \\
\hline - Pemasaran hasil & 50.000 & Pasar/ Pengepul \\
\hline Total biaya (Total cost) & 1.650 .000 & \\
\hline \multicolumn{3}{|l|}{ Pendapatan: } \\
\hline - Hasil pertanian & & \\
\hline Jagung & 650.000 & Musim Kemarau \\
\hline Padi & 1.150 .000 & Musim Hujan \\
\hline Kacang & 250.000 & Musim kemarau \\
\hline - Tan. kayu & - & Belum menghasilkan \\
\hline Total pendapatan (Total income) & 2.050 .000 & \\
\hline Selisih Pendapatan - Biaya (Income Difference - Costs) & 400.000 & \\
\hline
\end{tabular}

Sumber : Pengolahan data primer, 2015

Source : Primary data processing, 2015 
Tabel 7 menunjukkan bahwa jumlah keuntungan yang didapat hampir sama dengan jumlah biaya yang dikeluarkan. Hal ini mengindikasikan bahwa selama ini kegiatan pertanian yang dilakukan oleh petani/ masyarakat di Desa T'eba hanya cukup untuk memenuhi kebutuhan dan belum banyak memberikan keuntungan. Kondisi ini senada dengan data yang dilaporkan oleh Priyanto \& Diwyanto (2014) yang mengatakan bahwa masyarakat wilayah perbatasan tergolong berpenghasilan rendah, dan kebutuhan pangan mencapai $71,45 \%$ dari total pengeluaran.

\section{Persepsi Petani terhadap Agroforestri dengan Jenis Cendana, Kayu Papi dan Gaharu}

Pertanyaan terkait persepsi petani difokuskan pada pengetahuan petani tentang jenis cendana, kayu papi dan gaharu.
Pengetahuan yang dimaksud meliputi pengetahuan tentang teknik budidaya, nilai ekonomi, potensi dan kesesuaian jenis.

Tabel 8 mengindikasikan bahwa sebagian besar responden petani mengetahui teknik budidaya dan nilai ekonomi jenis cendana dan kayu papi, sementara untuk jenis gaharu mereka hanya sebagian kecil responden saja yang tahu. Terkait potensi, petani menganggap bahwa potensi cendana dan kayu papi sedikit, dan sebagian besar menganggap gaharu tidak ada di sekitar Desa T'eba. Untuk kesesuaian lahan dan kesesuaian sosial (tingkat penerimaan masyarakat) menunjukkan bahwa ketiga jenis tersebut sesuai. Apabila dilihat dari peta kesesuaian lahan untuk cendana maka lokasi Desa T'eba masuk kelas sesuai 3 dan 4 (Sumardi, Hidayatullah, Yuniati, \& Victorino, 2016).

Tabel 8. Persepsi petani terhadap agroforestri dengan jenis cendana, kayu papi dan gaharu Table 8. Perceptions of farmers on agroforestry with cendana, kayu papi and gaharu species

\begin{tabular}{lrrr}
\hline \multicolumn{1}{c}{ Parameter (Parameter) } & Persepsi petani (Perception of farmers) (\%) \\
Kayu Papi & Gaharu \\
\hline -Pengetahuan teknik budidaya: & & & \\
$\quad$ Tahu & $84 \%$ & $84 \%$ & $45 \%$ \\
$\quad$ Tidak Tahu & $16 \%$ & $16 \%$ & $55 \%$ \\
-Pengetahuan nilai ekonomi: & & & \\
$\quad$ Tahu & $71 \%$ & $74 \%$ & $23 \%$ \\
$\quad$ Tidak Tahu & $29 \%$ & $26 \%$ & $77 \%$ \\
-Potensi: & & & $-\%$ \\
$\quad$ Banyak & $15 \%$ & $13 \%$ & $17 \%$ \\
$\quad$ Sedikit & $81 \%$ & $87 \%$ & $83 \%$ \\
$\quad$ Tidak ada & $4 \%$ & $-\%$ & $67 \%$ \\
-Kesesuaian Lahan: & & & $33 \%$ \\
$\quad$ Sesuai & $96 \%$ & $96 \%$ & \\
$\quad$ Tidak sesuai & $4 \%$ & $4 \%$ & $68 \%$ \\
- Kesesuaian sosial: & & & $32 \%$ \\
$\quad$ Sesuai & $96 \%$ & $100 \%$ & $-\%$ \\
$\quad$ Tidak sesuai & $4 \%$ & & \\
\hline
\end{tabular}

Sumber : Pengolahan Data Primer, 2015

Source : Primary data processing, 2015 
Bersadarkan data tersebut dapat diketahui bahwa masyarakat Desa T'eba memiliki pengetahuan terkait budidaya ketiga jenis tersebut, meskipun perlu untuk ditingkatkan lagi. Demikian pula terkait pengetahuan terkait potensi ekonomi dari ketiga jenis tersebut, meskipun mereka mengatakan potensi ketiga jenis tersebut saat ini relatif sedikit, namun potensi ekonominya mereka akui tinggi apabila dapat dibudidayakan.

Selanjutnya terkait potensi yang ada dapat disimpulkan bahwa sebagian besar masyarakat menganggap bahwa ketiga jenis tersebut memiliki kesesuaian dengan kondisi lahan yang ada serta memiliki kelayakan sosial atau tingkat penerimaan oleh masyarakat yang sangat tinggi. Terutama untuk jenis cendana yang angkanya bisa mencapai $96 \%$ dan kayu papi 100\%. Hal ini cukup wajar, mengingat kedekatan masyarakat secara budaya dengan kedua jenis ini. Tanaman cendana adalah tanaman kehutanan yang sangat istimewa dan guna kayunya yang sangat tinggi (Sumanto et al., 2011). Cendana adalah tumbuhan tropika yang persebaran alaminya terpusat di kawasan provinsi Nusa Tenggara Timur (Wawo et al., 2008). Cendana merupakan spesies endemik asal Nusa Tenggara Timur yang bukan hanya bernilai ekonomi namun juga sebagai lambang pemersatu masyarakat dan kearifan lokal di Provinsi NTT (Kurniawan et al., 2013). Sedangkan kayu papi merupakan family santalacea yang memiliki sifat mirip cendana (Santalum album Linn.) dengan dalam hal ciri fisik kayu dan keharumannya. Kayu papi merupakan tanaman asli yang tumbuh di Desa T'eba pada sebagian lereng dan bukitnya. Sehingga jenis kayu papi ini telah dikenal baik oleh masyarakat. Demikian juga untuk jenis gaharu sudah ditanam oleh sebagian masyarakat di Desa T'eba, dan menunjukkan performa pertumbuhan yang cukup baik. Referensi pertanaman campuran antara cendana dan gaharu saat ini masih sangat terbatas, penelitian Wijayanto dan De Araujo (2011), pertumbuhan tanaman pokok cendana ( $S$. album) yang terbaik ditemukan pada pola agroforestri AF 2 (cendana, jati, mahoni, gaharu, jagung, singkong, kacang turis, dan labu) yang ditanam bersamaan dengan tanaman inang Sesbania spp, sedangkan pertumbuhan tanaman pokok cendana terendah ditemukan pada pola agroforestri AF 3 (cendana, jati, mahoni, gaharu, jagung dan labu) yang tidak ditanam bersama tanaman inang Sesbania spp. dan Cajanus cajan.

Dalam konteks revitalisasi paradigma dan kebijakan pembangunan pertanian baru dari pendekatan SDA dan teknologi ke arah pembangunan pertanian yang lebih holistik yakni meliputi SDA, SDM, teknologi dan kelembagaan (Elizabeth, 2007), agroforestri dapat dipandang dan ditempatkan sebagai cara untuk penguasaan lahan dan asset produktif, serta pengembangan basis sumberdaya pertanian. Hasil analisa mengenai aspek persepsi petani, aspek pengelolaan lahan dan aspek ekonomi di atas dapat dimanfaatkan oleh pihak terkait dalam merumuskan rencana atau strategi pengembangan sistem agroforestri, terutama terkait dengan kebijakan pemilihan jenis tanaman. Kendala utama bagi budidaya dan pengembangan ketiga jenis ini adalah pada orientasi masyarakat yang masih bertumpu pada tanaman pangan. Teknologi agroforestri sebagai alternatif solusi terbaik perlu untuk terus disosialisasikan ke masyarakat. 


\section{KESIMPULAN}

Cendana ( $S$. album) dan Kayu Papi (E.latifolia) di Desa T'eba memiliki potensi pengembangan berbasis agroforestri yang sangat tinggi dilihat dari aspek kemampuan dan pengetahuan masyarakat, serta kesesuaian lahan dan penerimaan sosial masyarakatnya. Sedangkan untuk jenis gaharu (G. versteegii) meskipun dari aspek pengetahuan masyarakat dalam hal budidaya rendah, namun masyarakat menilai jenis ini memiliki kesesuaian lahan dan kesesuaian sosial yang cukup tinggi. Pada aspek ekonomi, sebagian besar masyarakat (>70\%) menilai jenis cendana dan kayu papi memiliki nilai ekonomi tinggi, dan hanya $23 \%$ masyarakat yang memiliki pengetahuan terkait nilai ekonomi gaharu. Kendala paling utama adalah kebutuhan lahan untuk bercocok tanam. Pengembangan cendana, kayu papi dan gaharu dengan pola agroforestri, potensial untuk dikembangkan di Desa T'eba pada lahan seluas \pm 371 hektar.

Ucapan Terima Kasih : Ucapan terima kasih disampaikan kepada seluruh pihak yang telah membantu penelitian ini, khususnya kepada Sda. Martinus Lalus beserta keluarga, serta seluruh masyarakat Desa T'eba yang telah mendukung penelitian ini dengan sangat baik dan sabar.

\section{DAFTAR PUSTAKA}

Anonim. (2014). Profil Desa T'eba tahun 2014. Pemerintah Desa T'eba, Kecamatan Biboki Tanpah, Kabupaten $T T U$.

Banjarnahor, D. (2016). Tipologi Rumah Tangga Tani Sebagai Titik Masuk Pertanian Konservasi: Studi Kasus di Semi-Ringkai Tanzania. Jurnal Pertanian Tropik, 3(2), 100-108.

Bano Et, H. H. (2001). Makalah kajian. Berita
Biologi, Volume 5, (Masalah Cendana NTT), 469-475.

Elizabeth, R. (2007). Fenomena Sosiologis Metamorphosis Petani: Ke Arah Keberpihakan Pada Masyarakat Petani di Pedesaan Yang Terpinggirkan Terkait Konsep Ekonomi Kerakyatan SocioMetamorphosis Phenomenon of Farmers: Towards the Favor of Disadvantage Farmer's Community in R. Forum Penelitian Agro Ekonomi, 25(1), 29-42.

Fatmawati. (2011). Analisis Kebijakan Pengelolaan Cendana di Kabupaten Timor Tengah Selatan. Institut Pertanian Bogor.

Hendrisman, M., Sosiawan, H., \& Irianto, G. (2001). Kajian Evaluasi Lahan Untuk Pengembangan Cendana Dinusa Tenggara Timur. Berita, Volume 5,(Nomor 5), 599-603.

IUCN. Santalum album, Sandalwood. The IUCN Red List of Threatened Species 1998, versi 2015., e.T31852A9 Asian Regional Workshop (Conservation \& Sustainable Management of Trees, Vietnam, August 1996). The IUCN Red List of Threatened Species 1998. 1-6 (2015). www.iucnredlist.org. https://doi.org/http://dx.doi.org/10.2305/ IUCN.UK.1998.RLTS.T31852A966506 6.en

Kurniawan, H. (2012). Strata Tajuk Dan Kompetisi Pertumbuhan Cendana (Santalum album Linn.) di Pulau Timor (Crown Stratum and Growth Competition of Cendana (Santalum album Linn.) in Timor Island) Plan Pengembangan dan Pelestarian Cendana Provinsi Nusa Tenggara Timur Tahu. Jurnal Penelitian Kehutanan Wallacea, Vol.1 No.2, 103-115.

Kurniawan, H., Soenarno, \& Prasetyo, N. A. (2013). Kajian Beberapa Aspek Ekologi Cendana (Santalum album Linn.) Pada Lahan Masyarakat di Pulau Timor 
(Some Aspects of Ecology of Cendana (Santalum album Linn.) on Private Lands in Timor Island)* Hery Kurniawan 1 , Soenarno 2 , dan/ and Nurhuda Adi Prase. Penelitian Hutan Dan Konservasi Alam, Vo. 10 No., 3349.

Lassa, J. A. (2009). Memahami Kebijakan Pangan dan Nutrisi Indonesia: Studi Kasus Nusa Tenggara Timur 19582008. Journal of NTT Studies, 1((1)), $28-45$.

Leakey, R. R. B., Weber, J. C., Page, T., Cornelius, J. P., Akinnifesi, F. K., Roshetko, J. M.,... Jamnadass, R. (2012). Tree Domestication in Agrofrestry: Progress in The Second Decade (2003-2012). In D. Nair, P.K., Garrity (Ed.), Agroforestry - The Future of Global Land Use (pp. 145-173). USA: Springer.

Leki, S. (2010). Kajian Kebijakan Pertanian dalam Memenuhi Kebutuhan Dasar Penduduk di NTT. (W. Adiningtyas, Ed.). Kupang. Retrieved from www.perkumpulanpikul.or.id

Maguantara, Y. N. (2005). Pembenahan Tata Produksi Pertanian Pangan: Strategi dan Praktik Menuju Kedaulatan Petani. Jurnal Analisis Sosial, 10(1), 43-66.

McWilliam, A. (2005). Haumeni, Not Many: Renewed Plunder and Mismanagement in the Timorese Sandalwood Industry. Modern Asian Studies, 39(2), 285-320. https://doi.org/10.1017/S0026749X0400 158

Ngongo, Y., \& Marawali, H. H. (2016). Sistem Pertanian Lahan Pekaragan Mendukung Ketahanan Pangan Daerah Semi-Arid: Kasus Kawasan Rumah Pangan Lestari di Provinsi Nusa Tenggara Timur. Jurnal Pengkajian Dan Pengembangan Teknologi Pertanian, 18, No.3, 291-302.

Njurumana, G. N. D., Hidayatullah, M., \&
Butarbutar, T. (2008). Kondisi Tanah Pada Sistem Kaliwu Dan Mamar Di Timor Dan Sumba (Condition of Soil at Mamar and Kaliwu System In Timor and Sumba). Info Hutan, V(1), 45-51.

Priyanto, D., \& Diwyanto, K. (2014). Pengembangan pertanian wilayah perbatasan Nusa Tenggara Timur dan Republik Demokrasi Timor Leste. Pengembangan Inovasi Pertanian, 7(4), 207-220.

Rajati, T., Kusmana, C., Darusman, D., \& Saefuddin, A. (2006). Optimalisasi Pemanfaatan Lahan Kehutanan Dalam Kesejahteraan Sosial Ekonomi Masyarakat Desa Sekitar Hutan: Studi Kasus di Kabupaten Sumedang ( The Optimization of Forest Land Utilization to Improve Environment Quality and People Welfare Surrounding The F. Jurnal Manajemen Hutan Tropika, XII(1), 38-50.

Saparita, R. (2005). Perkembangan Komersialisasi Pertanian di Indonesia dan Proyeksinya 2005-2050. AGRISEP, Vol.4 No., 1-16.

Sumanto, S. E., Sutrisno, E., \& Kurniawan, H. (2011). Analisis Kebijakan dan Strategi Litbang Kehutanan dalam Pengembangan Cendana di Nusa Tenggara Timur (Policy Analysis and Forestry Research Strategy on Sandalwood Development in East Nusa Tenggara). Jurnal Analisis Kebijakan Kehutanan, Vol. 8(No. 3), 189-209.

Sumardi, Hidayatullah, M., Yuniati, D., \& Victorino, B. A. (2016). Analisis Kesesuaian Lahan Untuk Budidaya Cendana (Santalum album Linn .) di Pulau Timor. Jurnal Penelitian Kehutanan Wallacea, 5(1), 61-77. https://doi.org/10.18330/jwallacea.2016. vol5iss1pp61-77

Sutoro. (2015). Determinan Agronomis Produktivitas Jagung (The Agronomic Factors Determining Maize 
Productivity). Iptek Tanaman Pangan, 10(1), 39-46.

Wawo, A. H., Syarif, F., \& Budiardjo. (2008). Peranan Pohon Induk dan Pengaruh Pemupukan Daun Terhadap Pola Pertumbuhan Semai Cendana (Santalum album L.). Penelitian Hayati, 14, 5561.

Widiyanti, M. P., Purnaweni, H., \& Soeprobowati, T. R. (2013). Pengelolaan Cendana di Desa Asumanu, Kecamatan Raihat, Kabupaten Belu, Propinsi Nusa Tenggara Timur (NTT). In Pengelolaan Cendana di Desa Asumanu, Kecamatan Raihat, Kabupaten Belu, Propinsi Nusa Tenggara Timur (NTT) (pp. 13-18). Semarang: Program Studi Lingkungan UNDIP.
Wijayanto, N., \& De Araujo, J. (2011). Pertumbuhan Tanaman Pokok Cendana (Santalum album Linn.) pada Sistem Agroforestri di Desa Sanirin, Kecamatan Balibo, Kabupaten Bobonaro, Timor Leste Growth. Jurnal Silvikultur Tropika, 03(01), 119-123.

Yanti, R. (2012). Pendekatan Ekosistem Wanatani Semi Arid Khatulistiwa dalam Pengelolaan Pertanian Berkelanjutan (di Kecamatan Amarasi, Kabupaten Kupang, Nusa Tenggara Timur). Universitas Indonesia.

Zypchyn, K. (2012). Getting Back to the Garden: Reflections on gendered behaviours in home gardening. Earth Common Journal, 2(1), 19. Retrieved from https://journals.macewan.ca/index. php/earthcommon/article/view/60 
Jurnal FALOAK Vol. 2 No.2 Oktober 2018: 71-88 